\title{
Emission Properties and Stability of Internal Air Launch System
}

\author{
Jie Shu ${ }^{a, *}$, Dengcheng Zhang ${ }^{b}$, Lin $\mathrm{Li}^{c}$, Ang Qin ${ }^{d}$, Binlin Ma ${ }^{\mathrm{e}}$ \\ and Shuguang $\mathrm{Li}^{\dagger}$ \\ Aeronautics and Astronautics College, Air Force Engineering University, Shanxi, Xi'an 710038, \\ China. \\ a1349034152@qq.com, ${ }^{b}$ dengcheng_zhang@sina.com, c18091585911@163.com, \\ d18682931162@163.com, e171430198@qq.com, f774011513@qq.com
}

Keywords: internal air launch system, emission performance index, generalized stability, stability domain.

\begin{abstract}
Aiming at the characteristics of complex structure, changeable movement and the difference in emission and stability, put forward the emission performance index based on the study of internal air launch system; study the influence of the initial pitch angle of the carrier, characteristic diameter of stabilization parachute and some other characteristic parameters on emission properties; study the system's stability and put forward the concept of generalized stability through the research of kinetic equation, moreover, calculate stability domain through Monte Carlo calculation method.
\end{abstract}

\section{Introduction}

The internal air launch is a type of launch modes that aircraft loads with rockets and transport to the designated altitude, speed and heading, and then throw the rocket from the cabin by the predetermined way, at the same time, attitude and position will be adjusted by the parachute system, when the rocket attitude and monitoring parameters (such as rate of pitch etc.) meet the predetermined ignition requirements, ignite and parachute, complete the rocket launch. Figure. 1 is the internal air launch system mission profile.

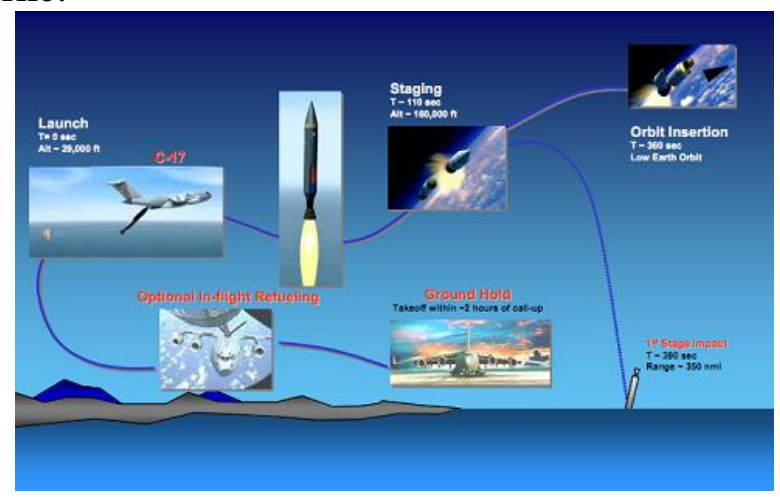

Fig. 1 Mission profile

Compared with the traditional land-based and sea-based launch, the air launch has multiple advantages of wide field, fast, mobile, cheap. So it has important application value in military and civil fields. At present, all countries in the world are developing the related technical ${ }^{[1-9]}$. The air launch system is different from the traditional one, which is composed of many objects, the structure is complex, the rocket is the unstable system when it rushes out of the cabin, so the launch performance and the stability are hot and difficult points.

\section{Description of Internal Air Launch System}

The internal air launch system is composed of a carrier $\left(B_{0}\right)$, a rocket $\left(B_{1}\right)$, a rope $\left(B_{2}\right)$ and a stable parachute $\left(B_{3}\right)$. 
According to the motion state of rocket, launching process is divided into three stages after opening the stable parachute. Named after system unlocking and before the rocket centroid move out of cabin for the first stage-- cabin traction phase (Case1), from rocket centroid out of cabin to rocket completely depart from cabin for the second stage-- rotating out of cabin phase (Case2), the phase after the separation of carrier and rocket for the third stage - separation phase (Case3). And make the stage that carrier leveling before the system unlock for the airdrop preparation phase (Case 0 ). The airdrop process is shown in figure.2.

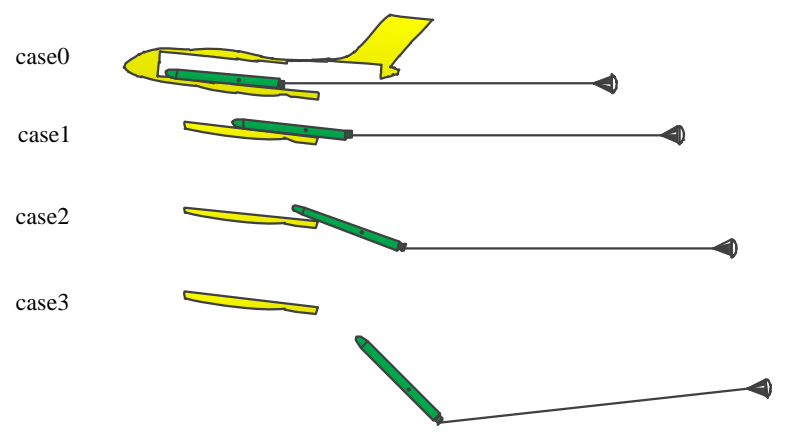

Fig. 2 Sketch map of Air-Launch

\section{The Concept and Calculation Method of Launching Performance}

\subsection{Basic Concepts}

The function of the internal air launch vehicle is to achieve the successful launch of the rocket under certain conditions. And achieving the ignition condition of predetermined index is the premise of the successful launch, therefore launching performance can be defined as: in the case of characteristic parameters determination, the ability that achieve the successful launch.

In order to determine the emission performance, we should determine the characteristic parameters of the system and the ignition condition, the structure and function of comprehensive system must be considered. Characteristic diameter of stable parachute $\left(D_{0}\right)$, aircraft initial pitch $\left(\theta_{\text {oinit }}\right)$,rocket centroid position $\left(l_{1}\right)$, distance from centroid to tail), the rocket quality $(m)$, the length of the rope $\left(l_{2}\right)$,carrier flight Mach number(Ma)and height $(\mathrm{H})$ are defined as characteristic parameters of the system. Feature parameter reference, $D_{0}=4.62 \mathrm{~m}, \theta_{\text {oinit }}=6^{\circ}, l_{1}=6.7 \mathrm{~m}, m=28 \mathrm{t}, l_{2}=50 \mathrm{~m}, M a=0.65, H=10 \mathrm{~km}$.In order to realize the successful launch, the pitch of $\operatorname{rockets}\left(\theta_{1}\right)$, yaw angle $\left(\beta_{1}\right)$,rate of $\operatorname{pitch}\left(\omega_{1 z}\right)$ and rate of $\operatorname{yaw}\left(\omega_{1 y}\right)$ must meet the following conditions: $\theta_{1} \in\left[0.5 \pi-\theta_{w}, 0.5 \pi+\theta_{w}\right], \beta_{1} \in\left[-\beta_{w}, \beta_{w}\right], \omega_{1 z} \in\left[-\omega_{1 z w}, \omega_{1 z w}\right]$, $\omega_{1 y} \in\left[\begin{array}{llll}-\omega_{1 y w}, \omega_{1 y w}\end{array}\right], \Delta_{w}=\left[\begin{array}{llll}\theta_{w} & \beta_{w} & \omega_{1 z w} & \omega_{1 y w}\end{array}\right]$, we define $\Delta_{w}$ as available domain of ignition. Normally, available domain is small, emission performance is better, but the realization of the successful launch is more difficult. Therefore, we should have an overall consideration of relationship between the system performance and function realization, and then determine the available domain.

\subsection{Calculation of Emission Performance}

The quantification of emission performance is a feasible method to determine the emission performance, so the following expressions can be used to quantify the emission performance, and $w$ is defined as the performance index.

$$
w=\sqrt{\frac{\left[\left(\theta_{1}-\frac{\pi}{2}\right)^{2}+\beta_{1}^{2}+\omega_{1 z}^{2}+\omega_{1 y}^{2}\right]}{\theta_{w}^{2}+\beta_{w}^{2}+\omega_{1 z w}^{2}+\omega_{1 y w}^{2}}}
$$

Formula:

$$
\left\{\begin{array}{l}
\theta_{1} \in\left[0.5 \pi-\theta_{w}, 0.5 \pi+\theta_{w}\right] \\
\beta_{1} \in\left[-\beta_{w}, \beta_{w}\right] \\
\omega_{1 z} \in\left[-\omega_{1 z w}, \omega_{1 z w}\right] \\
\omega_{1 y} \in\left[-\omega_{1 y w}, \omega_{1 y w}\right]
\end{array}\right.
$$




\subsection{Influence of Characteristic Parameters on Emission Performance and Its Influence Degree Analysis}

This paper studies the effect of the change of individual characteristic parameters on the performance of the emission, and the characteristic parameters are the same as above. In order to determine the available range of a single feature parameter variation under the baseline conditions, this section selects the range of variation of the characteristic parameters as shown in table 1.

Table 1 Variation Range of Main Parameters

\begin{tabular}{ccc}
\hline Characteristic parameters & Base value & Variation range \\
\hline Characteristic diameter of stabilization parachute $(\mathrm{m})$ & 4.62 & \pm 2.0 \\
Initial angle of pitch of carrier $\left(^{\circ}\right)$ & 6.0 & \pm 2.0 \\
Barycenter of rocket $(\mathrm{m})$ & 6.7 & \pm 0.4 \\
Mass of rocket $(\mathrm{t})$ & 28.0 & \pm 13.0 \\
Length of rope $(\mathrm{m})$ & 50 & \pm 5.0 \\
Initial height of carrier $(\mathrm{km})$ & 10 & \pm 4.5 \\
Initial Mach of carrier & 0.65 & \pm 2.0 \\
\hline
\end{tabular}

According to the formula (1), the influence of the change of the single characteristic parameters on the performance of the air emission is calculated, as shown in figure.3. The (a) characteristic curve for the pitch angle margin and time margin with stable umbrella diameter variation; (b) characteristic curve changes for the pitch angle margin and time margin with aircraft initial pitch angle; (c) for the pitch angle margin and time margin changes with the center of gravity rocket characteristic curve; (d) for the pitch angle margin and time margin with the characteristic curve of rocket mass change; $(\mathrm{E})$ for the pitch angle margin and time margin curve rope length change; (f) as the characteristic curve of the pitch angle margin and time margin with flight altitude change; $(\mathrm{g})$ as the characteristic curve of the pitch angle margin and time margin with the flight Maher number change.

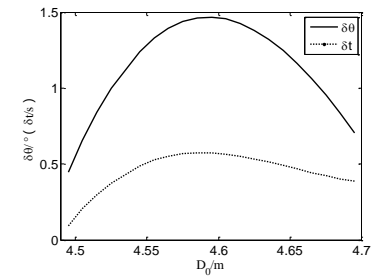

(a)

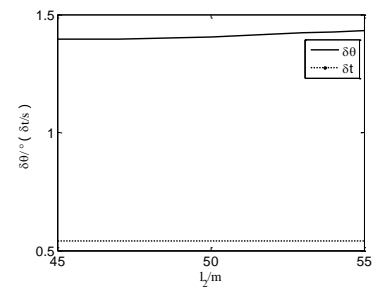

(e)

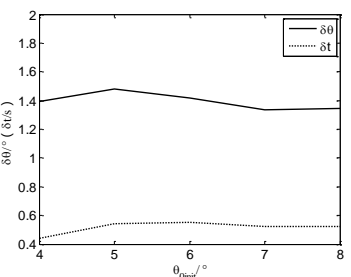

(b)

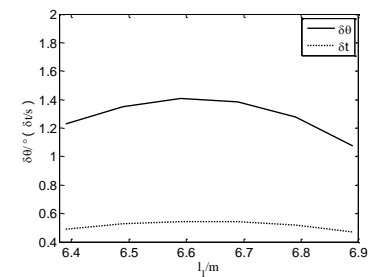

(c)

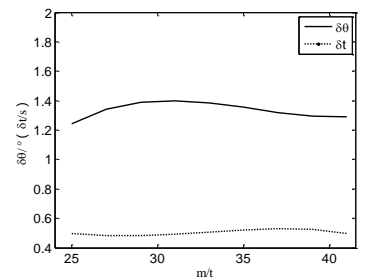

(d)

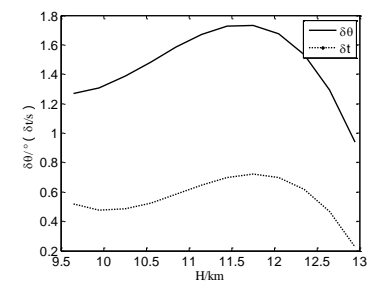

(f)

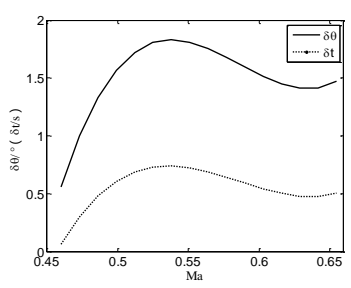

(g)

Fig. 3 Effect of characteristic parameters on emission performance

We use the following expressions to evaluate the influence of each characteristic parameter.

$$
\begin{aligned}
\Delta \delta_{i} & =\sqrt{\left(\delta \bar{\theta}_{i}-\delta \bar{\theta}_{0}\right)^{2}+\left(\delta \bar{t}_{i}-\delta \bar{t}_{0}\right)^{2}} \\
\delta \bar{\theta}_{i} & =\frac{\int_{\min \left(x_{i}\right)}^{\max \left(x_{i}\right)} \delta \theta_{i} d x_{i}}{\max \left(x_{i}\right)-\min \left(x_{i}\right)} \\
\delta \bar{t}_{i} & =\frac{\int_{\min \left(x_{i}\right)}^{\max \left(x_{i}\right)} \delta t_{i} d x_{i}}{\max \left(x_{i}\right)-\min \left(x_{i}\right)}
\end{aligned}
$$

In type:

$\delta \bar{\theta}_{\mathrm{i}}, \delta \bar{t}_{i}$ :The rate of change of the available margin to the i characteristic parameters;

$\delta t_{i}, \delta \theta_{i}:$ Represents the available margin for the i characteristic parameter;

$x_{i}:$ Represents the value of the i characteristic parameter; 
$\max \left(x_{i}\right), \min \left(x_{i}\right)$ :The maximum and minimum values of the $\mathrm{i}$ characteristic parameters;

I :I indicates that the characteristic parameters of the code, A, B, C, D, E, F, G, H;

Among them: the smaller the influence degree, the weaker the influence degree of the characteristic parameter. The results are shown in table 2.

Table 2 Variance ratio of usable margin

\begin{tabular}{ccccc}
\hline Characteristic parameters & Code & $\begin{array}{c}\text { Variance ratio of } \\
\text { pitch margin }\end{array}$ & $\begin{array}{c}\text { Variance ratio of } \\
\text { time margin }\end{array}$ & $\begin{array}{c}\text { Overall } \\
\text { index }\end{array}$ \\
\hline $\begin{array}{c}\text { Characteristic diameter of } \\
\text { stabilization parachute (m) }\end{array}$ & $\mathrm{A}$ & 1.1413 & 0.5626 & 0.2734 \\
Initial angle of pitch of carrier $\left(^{\circ}\right)$ & $\mathrm{B}$ & 1.3946 & 0.5160 & 0.0246 \\
Barycenter of Houston (m) & $\mathrm{C}$ & 1.2873 & 0.5150 & 0.1154 \\
Mass of rocket (t) & $\mathrm{D}$ & 1.3348 & 0.5033 & 0.0748 \\
Length of rope (m) & $\mathrm{E}$ & 1.4091 & 0.54 & 0.0091 \\
Initial height of carrier (km) & $\mathrm{F}$ & 1.4668 & 0.555 & 0.0685 \\
Initial Mach of carrier & $\mathrm{G}$ & 1.4952 & 0.5469 & 0.0954 \\
Overall evaluation & & A C G D F B E & \\
\hline
\end{tabular}

From the table, the influence of parameters on emission performance in the following order: the characteristic diameter of stabilizing parachute, rocket Center, Mach, rocket quality, flight altitude, the initial pitch angle, the length of the rope.

\section{The Generalized Stability and Stability Margin of Internal Air Launch System}

For air emission, change of characteristic parameters is not controllable, influence of emission performance is unpredictable, so the measure of stability of unstable system with traditional concept of stability is not desirable; for internal air launch system, it don't need to have stronger stability when rocket meet ignition conditions, so the measure of stability of air launch system with new parameters and methods is very necessary. The stability of air launch system can be interpreted as ability that the air launched multi-body system can launch successfully in the condition of stochastic wind disturbances and other uncertain factors. The ability to achieve this function is the system's generalized stability margin, we can use probability that system achieve the original function under disturbed condition to measure it.

Table 3 Statistic characteristics of random and distribution

\begin{tabular}{cccc}
\hline Characteristic parameters & Mean value & Deviation & Distribution \\
\hline Characteristic diameter of stabilization parachute $(\mathrm{m})$ & 4.62 & \pm 0.5 & Normal \\
Initial angle of pitch of carrier $\left(^{\circ}\right)$ & 6.0 & \pm 2.0 & Normal \\
Barycenter of rocket $(\mathrm{m})$ & 6.7 & \pm 0.1 & Normal \\
Mass of rocket $(\mathrm{t})$ & 28.0 & \pm 0.5 & Normal \\
Length of rope $(\mathrm{m})$ & 50 & \pm 1.0 & Normal \\
Initial height of carrier $(\mathrm{km})$ & 10 & \pm 1.0 & Normal \\
Initial Mach of carrier & 0.65 & \pm 0.5 & Normal \\
\hline
\end{tabular}

The generalized stability margin of internal air launch system can be calculated by the Monte Carlo method [10]. Monte Carlo is an experiment that based on stochastic process theory and mathematical statistics method, it can be used for solving math and physics and engineering technology. It conducts a number of tests of the model, process experimental data, determine the characteristics of the research process and parameter estimation. According to the distribution of the parameters, the degree of approximation of the problem can be determined from the probabilistic sense. In order to make the statistics to achieve sufficient accuracy, it is usually necessary to perform several hundreds of random sampling solutions. The specific method of calculating generalized stability margin is: through the research and comprehensive analysis of the predetermined design state, determine the possible range and probability distribution of characteristic parameters; then design the probability event, calculate 
the frequency of indexes that meet the performance of air launch system, the frequency is just the generalized stability margin of air launched system. According to the measurement of the characteristic parameters and the comprehensive evaluation, the statistical characteristics and distribution forms are selected as shown in table 3.

The selected feature parameters are the same as the previous ones. The available margin: $\theta_{w}=\beta_{w}=\omega_{1 z w}=\omega_{1 y w}$, the range of values: $[0, \pi / 18]$. performance index: $\mathrm{w}<1$, and the calculated results are shown in figure 4-figure 5.
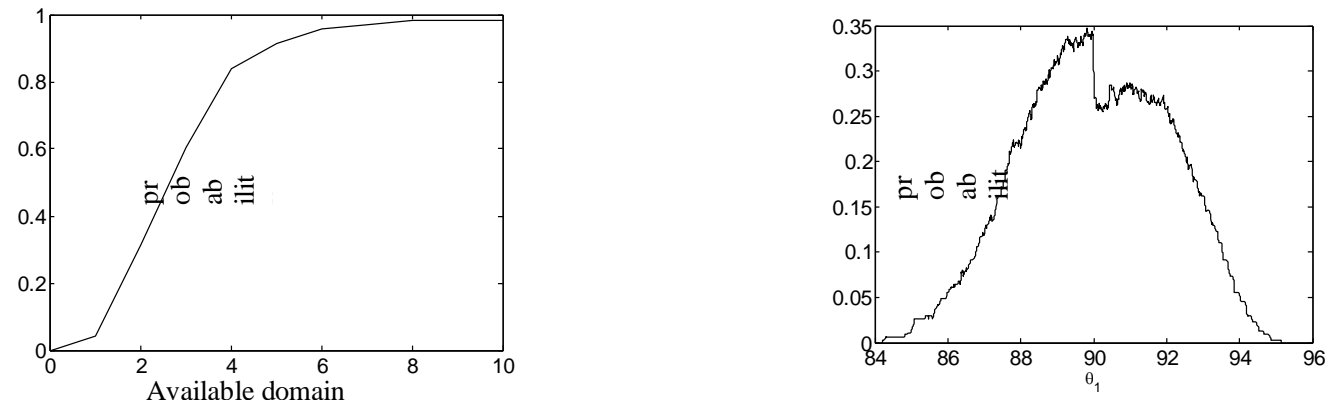

Fig. 4 Launching success rate on design point Fig. 5 Launching success rate on specific pitch angle

Figure 4 is a curve of mission success rate with the increase of available margin. As show in the curve that the probability increases slowly at the beginning, when the available margin is bigger than 1 and less than 4, the success rate of the system increases linearly with rapid firing rate, later, the increasing becomes slowly, and the figure shows that the probability of air launched launch system increases to $95.78 \%$ when the available range reach 6 , so in the design condition, the system has high anti-disturbance ability when.

Figure 5 is curve of mission success rate with the increase of pitch angle when available margin reach 6 .We can see from the curve that the probability distribution is not a normal probability distribution, and has two peaks. The success probability reach the maximum when degree angle of attack get 90 degree, but this conflict with the high launching success rate. So when design the ignition conditions, we cannot judge ignition condition based on specific pitch angle.

\section{Conclusion}

1) Put the concept and calculation method of launch performance based on the research of the internal air launch system.

2) Calculate the influence of characteristic parameters (carrier initial pitch angle, characteristic diameter of stabilization parachute. Etc.) On emission performance by means of simulation.

3) Propose the concept of the generalized stability of the internal air launch system, and calculate the stability margin of the generalized stability of the internal air launch system by using the Monte Carlo method.

\section{References}

[1]. Sarigul-Klijn M, Sarigul-Klijn N. A Study of Air Launch Methods for RLVs[C] // Proc. of AIAA Space 2001-Conference \& Exposition, Albuquerque, NM, Aug. 28-30, 2001, AIAA 2001-4619.

[2]. Kolega D J, Leger J E. Airborne Minuteman[C]. AIAA 1975-1388.

[3]. Leger J E. C-5A Air Launch of Minuteman I Missile[C] // Proc. of AIAA 1975 aircraft system and technology meeting, Los Angeles, California/August 4-7, 1975, AIAA 1975-969.

[4]. Schade C, Mosier M. The Pegasus Launch Vehicle New Capabilities and The Future[C]. AIAA 1994-1172.

[5]. Shi F S,Yuan B,Chen S N.Thought and Way of Develop Our Air Launch[J].Aerospace China,2003(2):34-38.

[6]. Marti Sarigul-Klijn, Ph.D. , Nesrin Sarigul-Klijn, Ph.D. Trade Studies for Air Launching a Small Launch Vehicle from a Cargo Aircraft[C] 43rd AIAA Aerospace Sciences Meeting and Exhibit, Reno, Nevada, 10-13 January 2005, AIAA 2005-0621. 
[7]. Weeks D J, Walker S H, Sackheim R L. Small satellites and the DARPA/Air Force FALCON program [J]. Acta Astronautic. 2005, 57.

[8]. Parkinson R C, Webb E. An-225/Hotol[C]. AIAA 1993-5169.

[9]. Yuichi Noguchi, Takashi Arime, Seiji Matsuda, at el. Japanese Air Launch System Concept and Test Plan[C] // Proc. of Aerodynamic Decelerator Systems Technology Conferences \& AIAA Aerodynamic Decelerator Systems (ADS) Conference: AIAA 2013-1331.

[10]. Qian X F.Missile Flight Aerodynamics [M]. BeiJing: Beijing Institute of Technology Press, 2000,8. (in Chinese) 